\title{
Occipital Lobe, Parietal Lobe, and Ventricular Ependymal Tumor
}

National Cancer Institute

\section{Source}

National Cancer Institute. Occipital Lobe, Parietal Lobe, and Ventricular Ependymal

Tumor. NCI Thesaurus. Code C131589.

An ependymal tumor affecting the occipital and parietal lobes and a brain ventricle. 